\title{
Surveying Paediatricians' Assessment of Childhood Bruising Patterns
}

\author{
Dr Chris Course ${ }^{1}$, Dr Alison Mott ${ }^{2}$, Dr David Tuthill ${ }^{1}$ \\ 'Noah's Ark Children's Hospital for Wales, Cardiff, U..K. \\ ${ }^{2}$ St. David's Hospital, Cardiff, U_K.
}

\section{Corresponding Author:}

Dr Chris Course

Noah's Ark Children's Hospital for Wales

University Hospital of Wales

Heath Park

Cardiff

CF14 4XW

chriscourse@doctors.org.uk

02920747747

\section{Keywords:}

Child Abuse

General Paediatrics

Community Child Health

Health Service

Paediatric Practice

\begin{abstract}
:
Bruising is a common finding among children, however distinguishing non-accidental injury from innocuous bruises poses a diagnostic challenge, and the consequences of misdiagnosis can be serious for both families and professionals. This study aimed to assess how paediatricians put their child protection training into practice, by asking them to score their concern of a diagnosis of non-accidental injury (NAI) across seven clinical scenarios of known provenance. Three scenarios showed bruising indicative of NAI, two were indicative of accidental bruising patterns, and two were common birth marks. Participants generally managed to identify the highrisk scenarios. However, despite high levels of child protection training across participants, there was considerable variation of opinion, with potential inaction on high-risk injuries and misinterpretation of common birth marks. These findings raise issues regarding the efficacy of child protection training; should there be formal assessment of capabilities similar to those used to verify resuscitation ability?
\end{abstract}

\section{Word Counts:}

Abstract: 148

Main Document: 1,078 


\section{What is known about this topic:}

Bruising is the commonest form of physical abuse presenting to paediatric services. Evidence suggests certain bruising patterns are more indicative of non-accidental injury in infants and children.

Misidentifying and inaction on suspicious, non-accidental bruising patterns can leave children at risk of further and more serious injury.

\section{What this study adds:}

Despite participants generally identifying scenarios with a high-risk of non-accidental injury, there was a large variation of opinion, unrelated to their amount of experience. The results suggest the need for formal and ongoing assessment of child protection competencies for those undertaking child protection training.

\section{Introduction}

Bruising is a common finding among children, arising from both accidental and nonaccidental injury (NAl). Paediatricians are asked to assess the history and clinical presentation of different bruising patterns, to determine their cause. Studies have tried to delineate accidental patterns of childhood bruising [1], and bruising patterns suggestive of NAI[2]. National Institute of Care and Clinical Excellence (NICE) published guidance on managing suspected child maltreatment and referral criteria[3]. The opinion paediatricians provide can have a profound impact on children and their families. Correct interpretation of skin lesions is vital: failure to recognise a nonaccidental bruise can lead to further significant harm to the child whilst misdiagnosing an innocent lesion as child abuse brings significant distress to the child and family.

Regular child protection training is a core competency for all paediatricians including those in paediatric training programmes. However, it is important to understand how this training is implemented in day-to-day practice. This study aimed to examine how paediatricians assess common skin lesions and bruises, which determines the next steps they take.

\section{Methods}

A slideshow (Microsoft Powerpoint ${ }^{\circledR}$ ) of seven images of known provenance was created by the authors. Three of the images were known NAI cases: a bruised ear in a two-month old baby; a slap mark on a toddler's cheek; and a bruised top lip in a sixweek old baby. Two were birth marks: a Mongolian blue-spot on a shin and café-aulait marks on thighs. The remaining two were bruises of accidental origin: a shin bruise on a seven-year-old child and a linear bruise on a thigh caused by the child hitting herself with a ruler edge. Each image was accompanied by a short explanation from the accompanying care-giver. Participants, who were all doctors (including paediatric, general practice and foundation year trainees), were invited from paediatric departments at Cardiff and Vale University Health Board to assess bruising from clinical slides. Each scenario was displayed for one minute.

A four-point scale was developed based on the referral criteria laid out in the NICE guideline on safeguarding in children[3] for the participants to score their concern that the underlying cause was NAI. A score of ' 1 ' related to there being no risk of NAI, '2' suggested the participant consider child maltreatment and was to be used where they felt more information was required. A score of ' 3 ' related to a strong suspicion of child 
maltreatment, whereas '4' related to an injury the participant felt was definitely child maltreatment.

Participants filled in an anonymised paper answer sheet. Results were then transcribed to a database (Microsoft Excel $\left.{ }^{\circledR}\right)$ for analysis.

In addition to their responses, the following demographic details were collected from the participants; current grade, years of experience in child health, current area of practice and level of child protection training. A Chi-Squared test was used to look for any differences between participants based on years of experience in child health, current grade, or level of child protection training completed.

\section{Research and Ethics}

This project was discussed with the Research and Ethics Department at UHW, who advised that ethical approval was not required. The project was registered with the Quality Improvement department.

\section{Results}

63 doctors participated, mainly paediatric trainees; their grades are shown in Table 1. Around half worked in general paediatrics (48\%), 39\% worked in a subspecialty and $13 \%$ worked in community paediatrics. Just over half had $(51 \%)$ worked in child health for more than five years. Almost all participants (90\%) had received child safeguarding training: $10 \%$ had completed level 1 training; $24 \%$ had completed level 2; and 57\% had completed level 3 or higher.

\begin{tabular}{|l|c|}
\hline Professional Grade & Number (\%) \\
\hline Foundation Year 1-2 & $5(8 \%)$ \\
\hline GP Specialty Trainee (GPST) Year 1-2 & $5(8 \%)$ \\
\hline Paediatric Specialty Trainee Year 1-3 & $18(29 \%)$ \\
\hline Paediatric Specialty Trainee Year 4-8 & $20(32 \%)$ \\
\hline Associate Specialist & $3(4 \%)$ \\
\hline Consultant & $12(19 \%)$ \\
\hline
\end{tabular}

Table 1: Professional grades of participants

The results from the participants are shown in Table 2 below. No statistically significant difference in responses was seen on comparing subgroups of participants defined by years of experience, current grade or defined by level of child protection training ( $p$ value ranges from $0.95-0.99$ ).

\begin{tabular}{|l|c|c|c|c|c|c|}
\hline Scenario & $\begin{array}{c}\text { 1: 'No } \\
\text { risk of } \\
\text { NAl' } \\
\mathbf{n}\end{array}$ & $\begin{array}{c}\text { 2: 'Consider } \\
\text { child } \\
\text { maltreatment' } \\
\mathbf{n}\end{array}$ & $\begin{array}{c}\text { 3: 'Strong } \\
\text { suspicion of } \\
\text { child } \\
\text { maltreatment' } \\
\mathbf{n}\end{array}$ & $\begin{array}{c}\text { 4: 'Definitely } \\
\text { child } \\
\text { maltreatment' } \\
\mathbf{n}\end{array}$ & $\begin{array}{c}\text { Median } \\
\text { score }\end{array}$ & Range \\
\hline $\begin{array}{l}1 . \quad \text { Ear } \\
\text { bruise, } \\
\text { two- } \\
\text { month old }\end{array}$ & 0 & 3 & 14 & 46 & 4 & 2 to 4 \\
\hline
\end{tabular}




\begin{tabular}{|c|c|c|c|c|c|c|}
\hline $\begin{array}{l}\text { Non- } \\
\text { accidental } \\
\text { injury }\end{array}$ & & & & & & \\
\hline $\begin{array}{l}2 . \quad \text { Slap- } \\
\text { mark, } \\
\text { toddler's } \\
\text { cheek } \\
\text { Non- } \\
\text { accidental } \\
\text { injury }\end{array}$ & 1 & 21 & 28) & 13 & 3 & 1 to 4 \\
\hline $\begin{array}{l}\text { 3. Shin } \\
\text { bruise, } \\
\text { seven- } \\
\text { year old } \\
\text { Accidental } \\
\text { injury }\end{array}$ & 47) & 15 & 0 & 1 & 1 & 1 to 4 \\
\hline $\begin{array}{l}\text { 4. Bruised } \\
\text { lip, six- } \\
\text { week old } \\
\text { Non- } \\
\text { accidental } \\
\text { injury }\end{array}$ & 2 & 16 & 29 & 16 & 3 & 1 to 4 \\
\hline $\begin{array}{l}5 . \\
\text { Mongolian } \\
\text { spot, leg } \\
\text { Birth mark }\end{array}$ & 53 & 9 & 0 & 1 & 1 & 1 to 4 \\
\hline $\begin{array}{l}\text { 6. Café- } \\
\text { au-lait } \\
\text { marks, } \\
\text { thighs } \\
\text { Birth mark }\end{array}$ & 24 & 29 & 8 & 2 & 2 & 1 to 4 \\
\hline $\begin{array}{l}7 . \\
\text { Accidental } \\
\text { linear } \\
\text { mark from } \\
\text { ruler } \\
\text { Accidental } \\
\text { bruise }\end{array}$ & 0 & 28 & 29 & 6 & 3 & 2 to 4 \\
\hline
\end{tabular}

Table 2: All 63 Participants responses

\section{Discussion}

Bruising is the most common injury in children who have experienced physical abuse[4], however discriminating between abusive bruises and those sustained from everyday activity or unintentional injury poses a diagnostic challenge[1]. Children at high risk for further serious abusive injury can present initially with relatively minor bruising[5]; these children must be identified appropriately to protect them from further harm. Research so far has highlighted bruising patterns in distinct age groups that should raise a serious concern of child maltreatment. Bruises to the ears, cheeks and lips/mouth in the infant and early mobile age-ranges[2] are concerning. By contrast accidental bruises on the legs, below the knees, are common in mobile children [1].

The participants in this study generally managed to identify those cases where suspicion of child maltreatment should be highest. However, despite there being a 
high level of child protection training amongst the study group, there was still considerable variation of opinion, even in those scenarios with bruising patterns more typical of child abuse. For example, in scenarios two and six which showed a slapmark on a toddler's cheek and a bruised lip on a non-mobile infant, the participants demonstrated they were considering child maltreatment as a potential cause, but we felt they did not demonstrate the appropriate level of concern. Additionally, common birth marks also showed the potential to confuse a few participants potentially prompting unnecessary safeguarding proceedings.

This study is limited by the use of clinical photographs and short case histories. In practice paediatricans have more information available from a paediatric assessment, including explanations for the bruising, presence of other risk factors and history of previous contact with social services, which should influence their decision making. The response 'consider child maltreatment' may be appropriate as it includes obtaining more information, even though in case 2 and 4 child maltreatment is highly likely whatever the explanation. It is unclear whether participants stated responses to the slides would equate into similar clinical decisions in real life.

This study has attempted to assess how clinicians put their child protection training into practice. It has demonstrated that despite high levels of training and awareness, there is some variation of opinion, even in scenarios indicative of child maltreatment. Intriguingly this seems unrelated to experience or level of child protection training, although larger evaluations would be needed to confirm or refute this. It raises the question of whether child protection training needs further standardisation between formats (for example between online learning and face-to-face courses) and whether there needs to be formal ongoing assessment of paediatric Safeguarding capabilities following training and evaluation techniques similar to those used to support and assess resuscitation or prescribing ability.

\section{References}

\section{Max 5}

1. Kemp, A.M., et al., Patterns of bruising in preschool children--a longitudinal study. Arch Dis Child, 2015. 100(5): p. 426-31.

2. Kemp, A.M., et al., Bruising in children who are assessed for suspected physical abuse. Arch Dis Child, 2014. 99(2): p. 108-13.

3. National Institute for Health and Care Excellence, NICE Guideline CG85: Child maltreatment: when to suspect maltreatment in under 18s. 2009.

4. Lynch, A., Child abuse in the school-age population. J Sch Health, 1975. 45(3): p. 1418.

5. Sheets, L.K., et al., Sentinel injuries in infants evaluated for child physical abuse. Pediatrics, 2013. 131(4): p. 701-7. 